\title{
Silane Primers as Adhesion Promotors for Coatings ${ }^{\dagger}$
}

\author{
François Xavier Perrin *, Anthony Grard and Lénaïk Belec \\ Laboratoire MAPIEM EA 4323, SeaTech-Ecole d'ingénieurs, Université de Toulon BP 20132, \\ 83957 La Garde CEDEX, France; anthony.grard@univ-tln.fr (A.G.); belec@univ-tln.fr (L.B.) \\ * Correspondence: perrin@univ-tln.fr \\ † Presented at the 15th International Symposium "Priorities of Chemistry for a Sustainable Development" \\ PRIOCHEM, Bucharest, Romania, 30 October-1 November 2019.
}

Published: 15 October 2019

Keywords: silane primers; sol-gel; silicone; adherence; polymer-metal assemblies

Sol-gel processing is a soft-chemistry method to obtain ceramic materials at low temperatures starting from molecular precursors in solution. The precursors can be inorganic salts $\left(\mathrm{Al}_{(}\left(\mathrm{NO}_{3}\right)_{3}\right.$, for example) but are mostly metal or silicon alcoxydes of a general formula $\mathrm{M}(\mathrm{OR}) \times$ with $\mathrm{M}=\mathrm{Si}, \mathrm{Ti}, \mathrm{Zr}$, $\mathrm{Hf}, \mathrm{Ce}, \mathrm{Al}$, etc. The formation of a network of oxides from $\mathrm{M}(\mathrm{OR})_{\mathrm{x}}$ involves hydrolysis and condensation reactions. Condensation is a complex process that involves the formation of a bridging oxo group through the elimination of an alcohol (alcoxolation) or water (oxolation) molecule. The formation of bridging hydroxo groups through the elimination of a solvent molecule (olation) can also occur when the maximum coordination of the metal atom, $\mathrm{N}$, is not satisfied in the alkoxide (i.e., $\mathrm{N}>\mathrm{z}$, the oxidation state of the metal). Silicon alcoxides, for which $\mathrm{N}=\mathrm{z}$, are thus not concerned by olation reactions. The development of inorganic sol-gel coatings has been driven by environmental and technical aspects: sol-gel coatings are non-carcinogenic, environmentally safe, stable, and strongly adherent on metal surfaces. The strong adherence to metal substrates has been related to the formation of covalent $\mathrm{M}-\mathrm{O}-\mathrm{M}^{\prime}$ bonds $\left(\mathrm{M}=\right.$ substrate and $\mathrm{M}^{\prime}=\mathrm{Si}$, $\mathrm{Ti}$, $\mathrm{Zr}$, etc.) that are produced during the drying stage. The most promising applications of such coatings are their uses as thin adherence promoter layers for a subsequent organic coating. The brittleness of inorganic sol-gel coatings can be mitigated by the incorporation of an organic component into the dried film structure. Silica-based hybrids have been studied much more frequently than titania-based or zirconia-based hybrids. This is due to the fact that silicon can readily be covalently linked to the organic component through $\mathrm{Si}-\mathrm{C}$ stable bonds. By using organoalkoxy silanes, $\mathrm{R}_{1 \times} \mathrm{Si}\left(\mathrm{OR}_{2}\right)_{4-x}$ with $\mathrm{x}=1$ or 2 , a silsesquioxane network built from $\mathrm{R}_{1} \mathrm{SiO}_{1.5}$ units $(\mathrm{x}=1)$ or polysiloxane linear chains $(\mathrm{x}=2)$ are obtained. The organic group $\mathrm{R}_{1}$ can be non-reactive (for example methyl or phenyl) or reactive (for example amino, oxirane or methacryloyl groups in $\gamma$-aminopropyltriethoxysilane, $\gamma$-glycidyloxypropyltrimethoxysilane and $\gamma$ methacryloyloxypropyltriethoxysilane, respectively). The reactive group $\mathrm{R}_{1}$ can attach to the polymer which is applied on the silane-treated metal. The organic component makes the gel network more flexible and, thus, less prone to cracking during heat treatment of the film. We will see in this presentation that $\gamma$-aminopropyltriethoxysilane, $\gamma$-APS, primers improve the wet durability of powder epoxy-steel joints that are prepared at high temperatures (around $200{ }^{\circ} \mathrm{C}$ ). It was shown that a bonding between epoxy and silane occurred when the silane sol was prepared at natural $\mathrm{pH}$ conditions but not under acidic conditions. XPS and FTIR results revealed a partial oxidation of the amine head group of $\gamma$-APS to amide but a few amino functionalities remain to react with oxirane groups of epoxy resin and strengthen the epoxy/silane interphase. Silane-based primers can also be used to increase the adherence of silicone rubber/metal assemblies. In this case, PDMS reinforced with fumed silica is often incorporated to the primer formulation as film former and in order to enhance the diffusion of the primer film into the silicone rubber matrix. We see that the nature and the amount of silica filler are decisive for the silicon-metal assembly to obtain a strong adherence. 
(C) 2019 by the authors. Licensee MDPI, Basel, Switzerland. This article is an open access article distributed under the terms and conditions of the Creative Commons Attribution (CC BY) license (http://creativecommons.org/licenses/by/4.0/). 